ISSN: 0213-3563

https://doi.org/10.14201/azafea202022923

\title{
EXPERIENCIA ÁLGICA Y EXPRESIÓN DOLIENTE: REFLEXIONES A PARTIR DE ABRAMOVIC ${ }^{1}$
}

\author{
Algic Experience and Suffering Expression: Reflections from Abramovic
}

\author{
Xavier EsCRIBANO \\ Universitat Internacional de Catalunya
}

Recibido: 2019-02-27

Aceptado: 2020-07-21

\section{RESUMEN}

Bajo la inspiración de la performance Lips of Thomas de Marina Abramovic, se examinan en este trabajo las fisuras y las paradojas que plantea un posible circuito interpersonal del dolor, en el que se distinguen al menos cuatro momentos: experiencia álgica, expresión doliente, reconocimiento y comportamiento de ayuda. Nos detenemos especialmente en el caso de una experiencia álgica a la que no corresponde sorprendentemente una expresión, y también en el caso de una expresión doliente que ha de superar múltiples dificultades para su reconocimiento. Mientras que el dolor agudo parece el verdadero actor que se despliega y manifiesta en la escena sin abrir apenas espacio a una modulación personal, el dolor crónico puede llegar a exigir una cuidadosa puesta en escena para alcanzar paradójicamente el reconocimiento de su mera realidad. Las múltiples fisuras y paradojas en la experiencia, expresión y reconocimiento del dolor pueden deberse, en definitiva, no a una disfunción casual de un circuito funcional y operante, sino al carácter disruptivo, destructivo o aberrante de una experiencia álgica que se manifiesta en último término como experiencia del mal.

Palabras clave: Experiencia álgica; expresión doliente; reconocimiento; compasión; dolor agudo; dolor crónico; performance; Abramovic.

1. Este artículo se enmarca dentro de los trabajos vinculados al proyecto: "Fenomenología del cuerpo y análisis del dolor”, financiado por el Ministerio de Economía, Industria y Competitividad: FFI2017-82272-P (Investigador principal: Agustín Serrano de Haro). 


\begin{abstract}
Under the inspiration of Marina Abramovic's performance Lips of Thomas, this work examines the fissures and paradoxes posed by a possible "interpersonal pain circuit", in which at least four moments can be distinguished: painful experience, expression of pain, recognition and help behavior. We will study in greater detail the case of a painful experience that does not surprisingly correspond to an expresion of pain. We'll also focus on the case of a painful expression that has to overcome multiple difficulties for its recognition. Whereas acute pain seems to be the true actor that unfolds and manifests itself in the scene, and it hardly opens up space for personal modulation, chronic pain can require a careful staging to paradoxically achieve the recognition of its mere reality. The multiple fissures and paradoxes in the experience, expression and recognition of pain may be due, ultimately, not to a casual dysfunction of a functional and operative circuit, but to the disruptive, destructive or aberrant character of a painful experience painful experience that ultimately manifests as an experience of evil.
\end{abstract}

Key words: painful experience; expression of pain; recognition; pro-behaviour empathy; acute pain; chronic pain; performance; Abramovic.

\title{
1. LA EXPERIENCIA LIMINAR
}

El día 24 de octubre de 1974, Marina Abramovic, artista nacida en la antigua Yugoslavia y considerada hoy día como una de las grandes referencias del Art Performance de las últimas décadas del siglo XX, presentó su obra Lips of Thomas, de dos horas de duración, en la galería Krinzinger de Innsbruck. Así describe de manera esquemática su propia actuación:

Ingiero lentamente 1 kilogramo de miel con una cuchara de plata.

Bebo lentamente un litro de vino tinto en una copa de vidrio.

Rompo el vidrio con mi mano derecha. afeitar.

Dibujo una estrella de cinco puntas en mi estómago con una cuchilla de

Me flagelo violentamente hasta que no siento el dolor.

Me tiendo en una cruz hecha de bloques de hielo.

El calor de un radiador suspendido sobre mi estómago hace sangrar la estrella cortada.

El resto de mi cuerpo comienza a helarse.

Permanezco tendida en la estrella durante 30 minutos hasta que el público interrumpe

la pieza retirando los bloques de hielo de debajo de mí $(1998,92)^{2}$.

2. Las traducciones son mías, salvo que se indique lo contrario. 
Esta escalofriante dramaturgia, que Abramovic desarrolla completamente desnuda e infligiendo a su cuerpo serias laceraciones, plantea múltiples interrogantes y cuestiones que se pueden abordar desde la óptica particular de una estética de lo performativo, al modo como lo hace lucidamente Erika Fischer-Lichte (2011). A los ojos de esta autora Lips of Thomas aparece como una obra arquetípica en su género, la performance de autoagresión. Un género que también practican, a partir de la década de los setenta del sigo pasado, artistas como Vito Acconci, Chris Burden o Gina Pane, entre otros, que se herían en escena, se intoxicaban con diversas sustancias o ejercían todo tipo de violencia en sus cuerpos, hasta llegar a correr verdaderos riesgos mortales en sus actuaciones.

Como puede verse en Lips of Thomas, Abramovic no actúa como una actriz interpretando los gestos de un personaje doliente desde la distancia y la neutralidad preconizada por los teóricos del teatro clásico, como en el texto programático de Diderot, Paradoxe sur le Comédien, en el que se insiste en la conveniencia de que el actor no se implique afectivamente en su personaje, sino que trate de transmitir lo más escrupulosamente posible los signos externos del sentimiento, sin comprometerse interiormente en lo expresado (Diderot 1929, 38). Abramovic se autolesiona de manera real, transforma visiblemente su cuerpo físico. Con total certeza, la sangre que gotea y mancha el suelo es real. No se trata de un personaje que finge sangrar, sino que lo que tenemos en escena es una persona sangrante. El artista regresa a su vida cotidiana con vestigios corporales de su actuación. La huella de la performance recorre dramáticamente toda su piel. Este comportamiento artístico hace radicalmente cierta la observación de Plessner de que, en el teatro, a diferencia de las artes plásticas, por ejemplo, el artista trabaja con el material de su existencia; "die Darstellung im Material der eigenen Existenz" (Plessner $1953,183)$. Es decir, con su propio cuerpo, y no con cualquier otra materia ajena a él, de la que pueda desprenderse o desentenderse.

En un primer análisis, salta a la vista la "ruptura de límites", que podrían considerarse como sobreentendidos en el ámbito de una actuación artística. Por enumerar solo algunos: se cruza el umbral del respeto o el cuidado a la propia integridad física del artista, se visita peligrosamente la frontera que separa la vida de la muerte, se traspasan los límites de la normal resistencia al dolor, se alteran los estados de conciencia hasta el extremo de quedar inconscientes en la propia escena, etc. El trabajo de Abramovic y las realizaciones escénicas de otros artistas que siguen la misma inspiración pueden entenderse como una investigación artística de los límites del cuerpo y de la 
conciencia ${ }^{3}$, además de conectar estéticamente con los postulados del teatro de la crueldad, de Antonin Artaud ${ }^{4}$. Pero también se rebasan otro tipo de límites, los que se refieren al propio espectador o a la concepción de la obra de arte. Tal como comenta Erika Fischer-Lichte, el visitante de una galería contempla las obras expuestas allí desde una cierta distancia, sin atreverse jamás a tocarlas; también el espectador de una obra de teatro sigue la acción de la escena, incluso con gran simpatía y emoción, sin jamás interferir, aunque lo que se presencie en el escenario sea el cruento asesinato de Desdémona a manos de Otelo. Las actitudes y comportamientos que rigen un acontecimiento artístico no coinciden con los que operan en la vida cotidiana porque, como todos asumimos de entrada "mientras el arte solicita una actitud estética, la vida exige un comportamiento ético. En ambos casos, se siguen distintas reglas" (Fischer-Lichte 2007, 35).

Ahora bien, en una obra como Lips of Thomas el espectador se ve obligado a situarse en un terreno más incierto, a ir más allá de una actitud estética, y comportarse éticamente. Se le exige un compromiso, que rompa la frontera invisible que separa el terreno de la contemplación estética desinteresada y la intervención práctica que disipa toda pretendida neutralidad o indiferencia. Al hacerlo así, paradójicamente, él mismo interviene en la escena, actúa en ella, y transgrede en este caso el límite entre los papeles tradicionalmente asignados al actor y al espectador, respectivamente. Si no queda clara la delimitación entre el terreno de lo estético y de lo ético, tampoco resulta evidente la distinción entre una actuación como la que aquí se refiere y el ritual transformativo de origen cultural ${ }^{5}$, en el que sorprendentemente se ven involucrados sin previo aviso los propios espectadores y de cuyo efecto en su propia persona ya no es posible desentenderse o distanciarse.

3. Así lo declara ella misma, en conversación con Thomas Mc Evilley: "el tema de mi trabajo serían los límites del cuerpo. Usaría la performance para empujar mis límites mentales y físicos más allá de la conciencia" (Abramovic 1998, 15).

4. "Una verdadera obra de teatro perturba el reposo de los sentidos, libera el inconsciente reprimido, incita a una especie de rebelión virtual (que por otra parte solo ejerce todo su efecto permaneciendo virtual) e impone a la comunidad una actitud heroica y difícil” (Artaud 2017, 34).

5. Según Bojana Pejic, Marina Abramovic fue la primera en introducir en el discurso del arte yugoslavo tras la Segunda Guerra Mundial el elemento "ritual": "Precisamente porque el ritual implica la presencia del cuerpo, solo puede pensarse seriamente sobre el proceso de re-ritualización del (en el) arte con la aparición del vídeo y de la performance. En el primer caso tiene que ver con la representación del cuerpo, en el segundo con la presentación del cuerpo" (Pejic 1993, 33). Al parecer, los chamanes siberianos cortan sus estómagos al modo como Marina Abramovic lo hace en Lips of Thomas (cf. Abramovic 2007, 22). 
Erika Fischer-Lichte destaca, sobre todo, el carácter liminar de este género de experiencia, el hecho de que coloca al espectador en una situación intermedia (in-between), dando origen a una inestabilidad perceptiva, que no puede determinar con claridad cómo debe percibir lo que está presenciando o cómo debe reaccionar ante lo que sucede. "Durante la entera duración de la performance, los espectadores fueron dejados en el estado de in-between, en el estado de liminalidad" (Fischer-Lichte 2007, 35). El espectador queda confrontado con fuertes emociones y reacciones fisiológicas que despiertan sin duda la necesidad de reflexionar: ¿qué es exactamente lo que está viendo, a qué tipo de acontecimiento está asistiendo? ¿cuál es el significado de la representación, cuál debería ser su reacción o su comportamiento, hay aquí alguna lección sobre el dolor o sobre la vida humana en su conjunto?

Además de la radicalidad de la propuesta y de su enigmático significado, que despiertan sin duda la perplejidad o el asombro, es posible destacar dos rasgos que -además de su profundo significado estético- hacen de la actuación que comentamos un interesante punto de partida para una meditación sobre el dolor y que van a centrar el interés de las siguientes páginas: en primer lugar, la inexpresividad de la artista a lo largo de toda su actuación, que pone en cuestión la conexión, al menos esperable, entre experiencia álgica y expresión doliente; $y$, en segundo lugar, la paradoja de un reconocimiento del dolor ajeno y de un comportamiento de socorro, que no ha sido de ningún modo invocado o solicitado y que puede ser inconveniente, dada la situación estética en la que en principio transcurre el evento. Se trata, pues, de subrayar la importancia de la expresión del dolor y algunas de sus paradojas.

\section{De LA INEXPRESIVIDAD AL GRITO}

La experiencia del dolor intensifica, sin duda, la eminente expresividad del cuerpo. Aunque la conexión entre experiencia álgica y expresión doliente no sea absolutamente necesaria -como podría ejemplificar, quizás, el caso de una extrema imperturbabilidad estoica o de origen ascético-solemos esperar cierta modulación de nuestra gestualidad, un tipo de comportamiento característico asociado a determinadas situaciones orgánicas intensamente molestas o desagradables, hasta tal punto que en ausencia de tales expresiones, es posible incluso dudar de la existencia misma del dolor, por más evidente que parezca su causa. Por ese motivo, ante la evidencia de las lesiones físicas en el cuerpo inerme de Abramovic, nadie entre el público podría sospechar de la veracidad de eventuales expresiones de dolor, si éstas se produjeran. Sin embargo, como observa Fischer-Lichte "cuando Abramovic aplasta la copa con 
su mano, recorta la estrella de cinco puntas en su piel, se estira en los cubos helados, no emite ni el más leve signo de dolor. Se limita a llevar a cabo acciones que transforman perceptiblemente su cuerpo; transgrede sus propios límites sin mostrar ningún signo de los estados internos desencadenados por ello" (Fischer-Lichte 2007, 34).

Ante la falta de confirmación expresiva de lo que parece una evidencia, se produce un desajuste, una ruptura en la conexión experiencia-expresión que parece difícilmente obviable. De manera paradójica, es más bien el público el que prorrumpe en exclamaciones, siente asombro, estupor, angustia, como si al dar expresión a un dolor que no sienten, prepararan el terreno para un comportamiento de auxilio, que el propio afectado paradójicamente no reclama. A este respecto, parece interesante anotar el hecho de que un interesante estudio neurológico acerca de la "experiencia del dolor vicario" pone de manifiesto que presenciar el dolor de otros provoca espontáneamente cambios fisiológicos, como dilatación de las pupilas, reflejos de huida, deceleración del ritmo cardíaco, incremento del ritmo respiratorio y de la conductividad de la piel, etc., que orientan la respuesta en el observador y le preparan para la acción (Giummarra Melita et al. 2016, 359). Pero en este caso, tales reacciones fisiológicas, o los mismos gestos de los espectadores, que apenas pueden inhibir un impulso a poner remedio a la situación que presencian, no vienen solicitados por la gestualidad del doliente, que de este modo no sólo establece una ruptura entre su propio dolor y la expresión, sino también entre el reconocimiento del dolor de otro y el despliegue de alguna conducta de socorro o alivio del mismo.

Por íntima e inefable que sea la experiencia álgica considerada en sí misma, es decir, aunque la consideremos esencialmente incomunicable, desde el punto de vista del espectador, la presencia de ciertos signos, que no son necesariamente palabras, que incluso pueden llegar a tener más autoridad que las propias palabras, manifiestan o corroboran la autenticidad de la experiencia ajena. Ahora bien, la conducta gestual doliente ha de ser ajustada: ni excesiva, ni deficiente. Del mismo modo que la impasibilidad estoica ante el dolor resulta desconcertante, hasta el punto de que un déficit de expresión -por decirlo así- arroja inmediatamente una sombra de duda sobre la existencia de ese mismo dolor, también el histrionismo o la exageración pueden desacreditar la autenticidad de la conducta doliente. El ajuste de la expresión a la experiencia parece asegurado cuando el dolor experimentado es tan agudo que apenas permite una modulación voluntaria del comportamiento. Lo que podría llamarse la "retórica del dolor" queda prácticamente excluida en los casos de dolor agudo: "El 'actor', en el caso del dolor agudo, es el dolor mismo, mientras que el paciente (y los otros) constituyen la audiencia 
presenciando el 'desarrollo de la trama' del dolor y anticipando su desenlace" (Brodwin 1994, pp. 78, 90). Así ocurre, paradigmáticamente, en la situación en que -como relata Chantal Maillard- nos vemos obligados a gritar de dolor: "Cuando el dolor se vuelve insoportable, las estrategias resultan inútiles. No hay distancia posible entre el yo que padece y su padecer. Cuando vence el dolor, sólo hay grito, y si éste se prolonga, la conciencia, esa conciencia que yo hubiese querido salvaguardar a toda costa y en todo momento, también termina siendo vencida, anulada" (Maillard 2003, 369s).Ahora bien, el exacto ajuste experiencia-expresión puede dejar de darse de una manera tan inmediata cuando su intensidad, su carácter crónico o su tipo permiten algún tipo de posicionamiento o actitud ante el mismo.

En algunos estudios realizados en el contexto de la atención sanitaria se ha puesto de relieve que no es infrecuente el caso de una cierta actuación relativa al dolor (performances of pain) por parte de los pacientes, ya sea para exagerar el dolor o bien para disimularlo. Así-se constata en tales estudios- personas que desean conseguir drogas narcóticas aprenden a imitar el comportamiento y la apariencia de personas afectadas por dolores agudos. Otros, al contrario, pueden intentar no manifestar dolor y comportarse dando muestras de fortaleza y de salud, porque no desean recibir atención médica, previendo, por ejemplo, una pérdida de independencia ( $c f$. Case 2014, 6-13). Ya sea a través de la ocultación o bien de la exageración, en uno y otro caso, se produce un desajuste en el "circuito interpersonal del dolor", que en principio tendría que conectar aproblemáticamente experiencia-expresión y reconocimiento. Por defecto o por exceso, experiencia álgica y expresión doliente no parecen hallarse en mutua correspondencia, como tampoco lo estarán el reconocimiento ajeno y comportamiento de ayuda o socorro subsiguientes.

La posibilidad de fingir dolor, ya sea para ocultarlo o para magnificarlo, es una consecuencia de la peculiar relación que cualquier persona, o bien uno de los pacientes a los que se refería el ejemplo anterior, mantiene con su propio cuerpo. Podría decirse que el ser humano no sólo es cuerpo y se identifica con él, sino que también tiene un cuerpo y puede de algún modo ponerlo a su disposición. Es interesante traer a colación la distinción que hace MerleauPonty, por ejemplo, entre el movimiento concreto y el movimiento abstracto del propio cuerpo. Mientras que el movimiento concreto responde a una situación dada, el movimiento abstracto define o crea él mismo la situación. Podría decirse que aquí se halla uno de los fundamentos del arte escénico: para nosotros existe siempre la posibilidad de romper de algún modo con cualquier situación dada en un entorno espacial o social y "deslizar" (Merleau-Ponty 1994, 121-122) el cuerpo en un personaje que asume actitudes o comportamientos ficticios. Desde luego, no se trata únicamente de una 
capacidad puesta al servicio de la escena, sino de una posibilidad inherente a nuestro comportamiento, que hace posible asumir una pluralidad de roles o de actitudes en situaciones dadas. La expresión del dolor se sitúa también en el punto de encuentro entre ambas dimensiones de la corporalidad: por una parte, la identificación con el cuerpo dolorido y la expresión espontánea de aflicción, huida o rechazo; y también, por otra parte, la posible modulación de la conducta doliente, que hace posible, por ejemplo, la exageración o disimulo del dolor.

A consecuencia de la posible desconexión o estilización entre experiencia álgica y expresión doliente podemos constatar, por parte del espectador del dolor, la existencia de actitudes tan polarizadas como, por un lado, la búsqueda de indicadores comportamentales (Abbey et al. 2014, 6-13) que adviertan de la existencia de un dolor no manifiesto en sujetos inexpresivos, como puede ser el caso de personas con demencia (Dowding et al. 2016, 152-162), o por otro, la desacreditación desconfiada ante un comportamiento que refiere o expresa explícitamente dolor, pero que no presenta una causa visible del mismo. En ocasiones, la fisura entre la experiencia del dolor y su reconocimiento por parte de un espectador ajeno procede de la inexpresión, de la expresión atípica o, incluso, de la gesticulación poco creíble del mismo. Podemos referirnos aquí, por ejemplo, en el ámbito médico, a múltiples casos, como el dolor neonatal, el dolor paliativo, el dolor en las personas con demencia o el dolor crónico, en los que la percepción o reconocimiento del dolor resulta cuando menos problemática ${ }^{6}$.

Para finalizar este apartado, podríamos preguntarnos si existe alguna expresión de dolor que resulte completamente inequívoca y evidente en sí misma. Una expresión tan reveladora e imperiosa que no permita al espectador ajeno ninguna duda respecto a la autenticidad de la experiencia y que le arranque, por decirlo así, sin ningún titubeo el reconocimiento y el gesto de socorro. Anatole Broyard, crítico literario y al mismo tiempo autor de un estremecedor ensayo autobiográfico desde la experiencia de la enfermedad, relata en uno de los pasajes de su libro una escena relativa al proceso terminal que también hubo de transitar su propio padre:

En ese momento, como si quisiera despedirse del médico, mi padre se hizo notar. Oímos un grito que sonó como si procediera de un ser que acabase de

6. El caso del dolor neonatal resulta paradigmático, por ese motivo, la investigación pediátrica en sistemas que permitan advertir signos comportamentales o indicadores fisiológicos susceptibles de interpretarse como manifestaciones de dolor especialmente en neonatos ingresados en la UCI resultan de gran actualidad: cfr. MACPHERSON, A., "Un sistema inteligente mide el dolor de un bebé”, La Vanguardia, 24/XII/2017. 
adquirir una voz en los recovecos más remotos del dolor, y como si en ese momento explorase ese dolor y esa voz al mismo tiempo, confundiendo intermitentemente el uno con la otra. Me quedé donde estaba, como un profesor de canto fascinado por un alumno que acabara de admitir un sonido ultraterreno, incapaz de decidir si era el sonido más bello que jamás hubiese oído o el más escalofriante. El médico volvió corriendo a la habitación... (Broyard 2013, 41).

Como si nos hubiéramos movido de un extremo a otro, y salvando las distancias entre los contextos "estético" y "ético" en el que transcurren ambas escenas, hemos pasado de la inexpresividad radical de Marina Abramovic, que genera perplejidad y dudas acerca del modo apropiado de responder, al grito desaforado y desgarrado de un enfermo doliente que parece arrancar necesariamente un comportamiento de ayuda. Sin embargo, a pesar de todo, tampoco la conexión entre expresión-reconocimiento-comportamiento parece asegurada en este caso, dado que el grito, que no puede pasar inadvertido -que, como todos los gestos expresivos constituye una solicitación, una pregunta, una invitación a responder (Merleau-Ponty 1994, 202)- manifiesta mi capacidad de llamar la atención, pero no asegura que esa llamada sea respondida. Así, el grito, ambiguo también como expresión radical de dolor, es la manifestación tanto de nuestra capacidad de convocatoria, como de la posibilidad de la indiferencia. En el grito -observa Erwin Straus- me siento fundamentalmente aceptado o rechazado, en él encuentro respuesta o pasividad, apoyo o resistencia: "Al gritar -en definitiva- experimentamos nuestro poder o nuestra debilidad” (Straus 1952, 686).

La misma Marina Abramovic no ha dejado de experimentar también con esta expresión radical del dolor, que es el grito. Así describe la performance titulada Freeing the Voice presentada en 1975 en el Studenski Kulturni Centar de Belgrado:

Me tumbo en el suelo con la cabeza inclinada hacia atrás.

Grito hasta que pierdo la voz.

Duración: 3 horas (Abramovic et al. 1998, 118) ${ }^{7}$

No sólo se trata de mostrar aquí hasta qué punto el dolor tiene la capacidad de desarticular y de arrasar el lenguaje, sino también el hecho que, desde el punto del espectador, la manifestación del dolor de otros, sobre todo cuando

7. Otras performances de la misma artista, como AAA-AAA - este caso en colaboración con Ulay, su compañero personal y artístico durante décadas- también abordan una problemática parecida: "Performance AAA-AAA. Gritamos uno en la boca del otro hasta que uno de nosotros pierde su voz” (Abramovic et al. 1998, 392). 
se lleva al extremo, es inaguantable. Cuando el grito de dolor se expresa en toda su virulencia, resulta insoportable, ello explica su relativa desaparición en algunas trabajos artísticos y medios de comunicación: "Nuestra incapacidad para escuchar a alguien gritando de dolor es la razón -comenta Bojana Pejic a propósito del trabajo de Abramovic- por la cual el grito es un tema frecuente en las artes visuales (pintura, escultura, fotografía o cine mudo) pero se suprime mayoritariamente en los medios o en las artes que dependen de la representación auditiva (radio, cine sonoro, televisión o video art)" (Pejic 1998, 31).

\section{LA DOBLE INVISIBILIDAD DEL DOLOR. EXPRESIÓN Y RECONOCIMIENTO}

Ninguna expresión doliente tiene asegurado desde el primer momento y de modo automático el reconocimiento del espectador ajeno y mucho menos aún un comportamiento de socorro o de auxilio. Si ello ocurre en el caso de las manifestaciones visibles y audibles del dolor agudo, con mayor razón aún podremos constatar algún tipo de fisura en la conexión expresión-reconocimiento en el caso de un dolor, al que a veces se denomina invisible, el llamado "dolor crónico" (invisible or unseen chronic pain), aquel cuya duración se prolonga más allá del tiempo esperado de curación y que, a diferencia del dolor agudo, no presenta causa fisiológica aparente. Esta invisibilidad de la causa que da origen al dolor redobla, por así decir, la invisibilidad intrínseca del dolor como experiencia íntima e inefable. La evidencia visual de las manifestaciones orgánicas o fisiológicas que acompañan al dolor agudo generan con facilidad respuestas simpatéticas (Brodwin 2013, 90). Por el contrario, la ausencia de síntomas fisiológicos que proporcionen una evidencia pública de su origen pone al dolor crónico con frecuencia bajo sospecha ante la mirada de los demás, hasta el punto de describirse el "síndrome del dolor crónico" como un tipo de desorden psicosocial (Clarke 2008). La credibilidad del dolor -como observa acertadamente Clarke- parece unida a la visibilidad de su causa (Clarke 2008, 660). A propósito de este problema, también encontramos en el trabajo performativo de Marina Abramovic una indicación interesante, ya que el cuerpo que "vemos" impertérrito en sus realizaciones escénicas no nos dice la verdad, no nos da toda la información, con lo cual se declara una cierta insuficiencia de ese acceso visual al otro y se remite a un ámbito de la experiencia innombrable e intransferible, precisamente la experiencia individual y aislante del propio dolor (Pejic 1998, 31).

Ahora bien, cuando a la experiencia inefable del dolor se le añade su no reconocimiento, entonces la resonancia afectiva negativa, asociada al 
fenómeno álgico, se ve avivada e intensificada. En efecto, uno de los motivos que puede generar un sufrimiento añadido para un paciente es que su dolor no sea reconocido. El paciente experimenta tal situación como una pérdida de credibilidad ante los demás, finalmente no se atreve a hablar de su propio dolor y cae en el aislamiento: "[L]os pacientes con dolor crónico pueden llegar a creer después de un tiempo que ya no pueden hablar a los otros de su angustia. [...] la persona acaba desconfiando de su propia percepción de la realidad y el aislamiento social se añade al sufrimiento personal" (Cassel 1982, 641). En algunos casos, el paciente de un dolor crónico sin causa fisiológica aparente puede ver cómo se habla de su dolor como de un dolor "meramente psicológico" o bien puede verse acusado de estar fingiendo, de representar un papel, de hacer teatro: "El sufrimiento puede darse cuando los médicos no validan el dolor del paciente. En ausencia de una enfermedad, los médicos pueden sugerir que el dolor es psicológico (en el sentido de no ser real) o que el paciente está 'fingiendo'” (Cassel 1982, 641).

En diversos estudios ha sido puesto de relieve cómo la persona que padece un dolor crónico en ocasiones debe realizar un arduo esfuerzo para desarrollar una narrativa creíble del propio dolor, para ser tomada en serio, ante la actitud de reserva o de desconfianza del personal sanitario o de otros interlocutores no especializados. Dicho de otra manera, y aunque parezca paradójico, para no tener que soportar el degradante trato de ser puestos bajo sospecha como fingidores, deben elaborar cuidadosamente su comportamiento, medir sus palabras y sus gestos, crear un personaje convincente y revelador, que responda a las expectativas estereotipadas acerca de cómo debe aparecer o manifestarse una persona que pasa por un trance de dolor permanente (Hansson et al. 2011, 661; Clarke 2008, 661). ¿Acaso no puede realizarse un cierto contraste entre la performance de Abramovic en la que se autoinflinge dolor y no lo expresa y la performance prácticamente inversa de un paciente que ha de poner en escena, modular, estilizar o incluso intensificar la expresión doliente en búsqueda de credibilidad y de reconocimiento?

\section{DEL DOLOR CRÓNICO A LA INDIFERENCIA CRÓNICA}

Una de las las causas plausibles de la alarmante indiferencia que muchas personas demuestran ante los padecimientos reales de otras personas en las grandes ciudades de Occidente, podría ser, como ha sido señalado por el sociólogo Richard Sennet, la inmersión en un mundo de virtualidad creciente, especialmente visual. La insensibilidad ante el dolor real de otros resulta un rasgo distintivo de nuestra época, y más concretamente, del modo de vida en 
las grandes metrópolis, convertidas en ágoras visuales, en las que se produce una sobreexposición a imágenes de dolor virtual, así como un consumo ingente de sexo virtual, que paradójicamente inhibe, por embotamiento y adormecimiento de la conciencia corporal, la respuesta adecuada ante las situaciones reales (Sennet 1997, 18ss). Ante la falta de conciencia de la propia insuficiencia, relacionada con las imágenes prototípicas de plenitud que saturan los medios de comunicación de masas y, por otra parte, la privación sensorial que comporta la hipertrofia de la mediación tecnológica, Sennet aboga, como tarea verdaderamente civilizadora, por la necesidad de confrontarnos con experiencias en las que podamos descubrir la propia incoherencia, insuficiencia y fragilidad. Enfrentarnos a una percepción alterada de nosotros mismos, ponernos en contacto con nuestra propia limitación o insuficiencia, hacernos capaces de reconocer el dolor del otro son tareas prioritarias -según Sennet- del esfuerzo civilizatorio contemporáneo. En este sentido la corporización escénica del dolor y la vulnerabilidad podría considerarse un modo efectivo de llevar a cabo la tarea civilizatoria preconizada por Sennet. En efecto, se trataría de usar el cuerpo y sus sufrimientos para comunicar e influir en el mundo social, generando una transformación de actitudes o de hábitos perceptivos. Los mensajes corporales de esta "retórica del dolor" hablarían con una autenticidad y poder de los que carecen los mensajes verbales.

Podemos preguntarnos, efectivamente, si la encarnación performativa del dolor por parte de Abramovic puede ser enmarcada en un proyecto ético, como el de responder a la creciente virtualización del cuerpo y a la pasividad o indiferencia sensorial ante el dolor de los demás, en el ágora visual del que habla Sennet. La cuestión es si necesitamos alguna forma de ficción, más precisamente la encarnación teatral del dolor y su retórica, para generar una transformación de la actitud y para restablecer la corriente en el circuito de la reciprocidad. Para comenzar, ello nos colocaría ante una nueva paradoja en la relación entre el dolor, su expresión (o retórica) y el supuesto reconocimiento de este: anteriormente habíamos formulado la paradoja de un dolor realmente experimentado, el dolor crónico, doblemente invisible, que requiere de una simulación teatral, de una puesta en escena convincente, para poder ser reconocido. Ahora presentamos el hecho, no menos paradójico, de que un exceso de dolor virtual en los medios de comunicación, nos lleve, a nivel social, a una insensibilidad para el dolor real de otro, y que sea necesaria una performance del dolor, para aprender a sentirlo. Nos estaríamos moviendo de la insensibilidad de un dolor que es realmente sentido, a la visibilidad de un dolor ficticio que no es sentido; del caso restringido de una insensibilidad 
médica, al caso generalizado de una insensibilidad social, "del dolor crónico de otros a la anestesia crónica de nosotros mismos” ${ }^{\text {. }}$.

\section{CONCLUSión}

En el ágora visual que habitamos, estamos acostumbrados a presenciar desastres, catástrofes, guerras y desdichas que ocurren al otro lado de la pantalla, a veces en la lejanía, otras en una relativa proximidad. A un lado, pues, tenemos un conjunto de imágenes de dolor y de sufrimiento, a otro lado, nuestra incapacidad para actuar. Somos espectadores de catástrofes frente a las cuales no sabemos cómo reaccionar y esta incapacidad probablemente afecta al modo como miramos al mundo y su sufrimiento: lo miramos como imagen ${ }^{9}$. En este contexto de virtualización de nuestra relación con el mundo, la performance de Abramovic en la que se produce una encarnación o corporización del dolor y que obliga al espectador a actuar tiene, sin embargo, una lectura ambigua: puede interpretarse como una ruptura del encantamiento de lo virtual, de la pasividad del espectador y una invitación a entrar en el mundo real del sufrimiento ajeno; o puede muy bien ser interpretado de modo casi inverso como una inmersión del espectador en el propio espectáculo, el ejercicio de un papel que no es exactamente ético, sino más bien el de un nuevo personaje de la escena: el de un espectador que sale al rescate de un actor en peligro. La acción, que en la primera interpretación parecía una ruptura de la virtualidad, comparece, en esta segunda interpretación, como aquello mismo que sufre una metamorfosis en lo virtual. No en vano, las campañas de ayuda o los festivales benéficos -más allá de sus intenciones loables-forman parte de ese gran teatro mediático en el que se ha convertido el mundo.

El dolor no sólo tiene la capacidad de molestarnos, incomodarnos o agobiarnos momentáneamente, sino que, dado su carácter aversivo y disruptivo, llega hasta el extremo de socavar o de producir una crisis en la experiencia que tenemos de nosotros mismos, del mundo que nos envuelve y de nuestras relaciones con los demás. En el caso extremo del dolor invasivo, la atención

8. El trabajo seminal de esta investigación fue presentado y discutido en el marco de un seminario que tuvo lugar en Hollandscollege de Katholieke Universiteit Leuven (Bélgica) en febrero de 2018 con el título de "Mimic of Pain”. En el curso de la discusión recibí interesantes aportaciones de varios colegas y profesores, muy especialmente de Roland Breeur, organizador del evento, y de Nidesh Lawtoo, a quien debo la reflexión que antecede y la expresión a la que hace referencia esta nota.

9. “Agradezco a Roland Breeur la sugerencia, en la discusión de este trabajo, de esta línea de reflexión”. 
de nuestra conciencia, que habitualmente se dirige a los asuntos que nos interesan o nos preocupan, sufre una torsión radical (Serrano de Haro 2016) y se ve obligada a retraerse del mundo y volver sobre sí misma, enclaustrada subjetivamente en su propia y desagradable vivencia. Es este carácter disruptivo y aversivo del dolor el que quizás nos proporcione una última clave para comprender las fisuras y paradojas del circuito interpersonal del dolor. Animados o inspirados inicialmente por la performance Lips of Thomas de Marina Abramovic, hemos señalado posibles desconexiones o interrupciones entre los momentos constitutivos de este proceso, enfatizando de manera especial los retos que plantea la misma expresión doliente, sometida a posibles disimulos o exageraciones. Ahora bien, si atendemos en último término al carácter disruptivo del dolor, a la pérdida de mundo o destrucción de la experiencia que conlleva, cabría preguntarse si no se trata únicamente de accidentales disfunciones en un circuito dado, en cuyo seno fluirían la expresión y el reconocimiento, sino de la inadecuación misma del propio circuito, de la imposibilidad, en el caso del dolor, de ser expresado adecuadamente, de ser reconocido justamente, de ser remediado proporcionalmente. En definitiva, nos pondríamos ante la idea de un poder destructivo sin paliativos que sería la manifestación del propio mal.

\section{Bibliografía}

Aвbey, J. et al. (2004). "The Abbey pain scale: a 1-minute numerical indicator for people with end-stage dementia”. International Journal of Palliative Nursing, vol. 10, n. 1, pp. 6-13.

Abramovic, M. et al. (1998). Marina Abramovic: Artist Body: Performances 19691997. Milán. Edizioni Charta.

Artaud, A. (2017). El teatro y su doble. Madrid. Edhasa.

Brodwin, P. E. (1994). "Symptoms and Social Performances: The Case of Diane Reden”. en Good, M-J. D. et al. (eds.). Pain as Human Experience. An Anthropological Perspective. Berkeley-Los Angeles-London. University of California Press, pp. 77-99.

Broyard, A. (2013). Ebrio de enfermedad. Segovia. Eds. La Uña Rota. Traducción de M. Martínez-Lage.

CAse, G. A. (2014). "Performance and the Hidden Curriculum in Medicine". Performance Research, vol. 19 n. 4, pp. 6-13

Cassel, E. J. (1982). "The Nature of Suffering and the Goals of Medicine". The Nerw England Journal of Medicine, vol. 306, n. 11, pp. 639-645.

Clarke, K. A. (2008). "A phenomenological hermeneutic study into unseen chronic pain”. British Journal of Nursing, vol. 17, n. 10, pp. 658-663. 
Diderot, D. (1929). Paradoxe sur le Comédien. París. Librairie Plon.

DowDing, D. et al. (2016). "Using sense-making theory to aid understanding of the recognition, assessment and management of pain in patients with dementia in acute hospital settings”. International Journal of Nursing Studies, vol. 53, pp. 152-162.

Fischer-Lichte, E. (2007). "Performance Art - Experiencing Liminality”, en Abramovic, M. 7 easy pieces. Milano. Charta, pp. 33-45.

Fischer-Lichte, E. (2011). Estética de lo performativo. Madrid. Abada Editores. Traducción de Diana González Martín y David Martínez Perrucha.

Giummarra Melita J. et al. (2016) “The Social Side of Pain: What does it Mean to Feel Another's Pain?” en Rysewyk (ed.) Meanings of Pain. Cham. Springer International Publishing, pp. 355-373.

Hansson, K. S. et al. (2011). "The meaning of the experiences of persons with chronic pain in their encounters with the health service". Scandinavian Journal of Caring Sciences, vol. 25, pp. 444-450.

Maillard, Ch. (2003). "Sobre el dolor". Humanitas. Humanidades Médicas, vol. 1, n. 4, pp. 353-360.

Merleau-Ponty, M. (1994). Fenomenología de la percepción. Barcelona. Ed. Península. Traducción de Jem Cabanes.

PeJIC, B. (1993). “Being-in-the-body. On the spiritual in Marina Abramovic's art”, en Meschede, F. Marina Abramovic. Stuttgart. Edition Cantz.

Pejic, B. (1998). “Bodyscenes: an Affair of the Flesh” en Abramovic, M. et al. Marina Abramovic: Artist Body: Performances 1969-1997. Milano. Edizioni Charta, pp. 26-40.

Plessner, H. (1953). “Zur Anthropologie des Schauspielers” en ÍDEM, Zwischen Philosophie und Gesellschaft. Ausgewäblte Abhandlungen und Vorträge. Bern. Francke Verlag, pp. 180-192.

Serrano de Haro, Agustín. (2016). "Pain Experience and Structures of Attention: A Phenomenological Approach” en S. VAN RYSEWYK (ed.) Meanings of Pain. Cham. Springer International Publishing, pp. 165-180.

SENNET, R. (1997). Carne y piedra. El cuerpo y la ciudad en la civilización occidental. Madrid. Alianza Editorial.

STRAus, E. (1952). “The Sigh: An Introduction to a Theory of Expression”, Tijdschrift voor Philosophie, vol. 14, n. 4, pp. 674-695. 